\title{
Argentina 1976-1983: la oposición obrera a la dictadura en la memoria de cinco trabajadores
}

\author{
Pablo A. Pozzi* \\ Universidad de Buenos Aires
}

\begin{abstract}
Resumen
La actitud de la clase obrera argentina frente a la dictadura militar que se inició en 1976 ha sido objeto de numerosas discusiones. A través del análisis de las entrevistas, este trabajo se propone estudiar la articulación entre memoria, resistencia, cohesión y conciencia de clase. La estructura de la narración, la adjetivación utilizada para transmitir una experiencia, las imágenes a las que se recurren, todo conforma una visión clasista de articular la memoria obrera. En la misma, las tradiciones, el lenguaje, y el imaginario conforman no sólo una forma de transmisión de una experiencia resistente, sino también lo que podríamos denominar una memoria clasista y por ende marcada por la guerra de clases.
\end{abstract}

\section{Palabras clave}

resistencia, clase obrera, tradiciones, dictadura, imaginario

\begin{abstract}
The reaction of the working class to the 1976 Argentine military dictatorship, has been the subject of numerous discussions. Through the analysis of interviews this article proposes to study the relationship between memory, resistance, cohesion, and class conscience. The narrative structure, the adjectives used to transmit personal experiences, the images used conform a class vision that articulates worker memory. Tradition, language, and imaginary conform a specific form of transmitting a resistant experience, and also what can be termed a class memory.
\end{abstract}

\section{Keywords}

resistance, memory, labor, traditions, dictatorship

\footnotetext{
* PhD en Historia (SUNY at Stony Brook, 1989) y Profesor Titular de la Cátedra de Historia de los Estados Unidos de América, en el Departamento de Historia de la Facultad de Filosofía y Letras, Universidad de Buenos Aires (Argentina). Director Instituto de Estudios Interdisciplinarios de América Latina (INDEAL), Facultad de Filosofía y Letras (UBA). Entre muchas otras, se destacan sus obras Los setentistas. Izquierda y clase obrera, 1969-1976 (Eudeba, 2000), Por la sendas argentinas. El PRT-ERP, la guerrilla marxista (Eudeba 2001) y Huellas Imperiales. Estados Unidos de la crisis de acumulación a la globalización capitalista (Editorial Imago Mundi 2003).
} 
Hace ya más de veinte años, los trabajadores ferroviarios argentinos se declararon en huelga en contra de la privatización de las líneas férreas. Sin la colaboración del sindicato, que participaba de la venta de los ferrocarriles, estos trabajadores llevaron adelante una lucha de más de un mes y medio con cualidades heroicas. Sabotajes, actos relámpagos, y movilizaciones fueron algunas de sus formas de lucha. La principal consigna del conflicto era "si en el '61 no pudieron, en el "91 mucho menos". La consigna hacía referencia a la heroica huelga de 1961 en contra de la reestructuración ferroviaria. Lo notable es que la huelga de 1961 se perdió. Por ende, si en 1961 si "pudieron" ¿a qué se estaban refiriendo los obreros de 1991? Una de las respuestas posibles es que, para los trabajadores, lo que se recuerda no es tanto el resultado concreto de tal o cual lucha, sino más bien la sensación poderosa de haber luchado, de haber participado en un gran movimiento clasista conformando una memoria determinada.

En este sentido, la consigna ies verdad o es mentira? En realidad es ni una cosa ni otra. La consigna es cómo un grupo social ha construido una memoria a partir de una experiencia concreta. Desde el punto de vista de los hechos, la consigna no es veraz; pero desde el punto de vista de la subjetividad obrera se revela como una "estructura de sentimiento" real. Por ende, para el historiador, el criterio de "veracidad" no depende de un posicionamiento positivista sino más bien del objetivo de su investigación. Así, por ejemplo, uno de los momentos más recordados de la historia obrera argentina fue la toma del frigorífico Lisandro de la Torre en 1959. ${ }^{1}$ Si todos trabajadores que testimonian haber participado de esa lucha lo hubieran efectivamente hecho, serían decenas de miles. Una vez más ¿es falso lo que nos cuentan? En términos objetivos puede serlo y tenemos que desarrollar controles que permitan separar la invención de la realidad. Pero desde el punto de vista de la memoria esto dice mucho más que si en realidad hubieran participado; nos sugiere que este hecho fue central en la experiencia y la subjetividad de los trabajadores argentinos.

En la práctica real de los grandes grupos sociales, la construcción de una memoria particular de estas experiencias de lucha cumple dos funciones claves. La primera es como cohesión grupal que define un "nosotros" y un "ellos", una forma de comportamiento entendido como "correcto", y toda una concepción cultural "clasista" que abarca y subyace elementos ideológicos y políticos. O sea, esta "memoria" es central a la existencia de una identidad determinada. La segunda es que estas prácticas y memorias constituyen la materia prima del acervo de experiencia que permite la continuidad de luchas y actividades en pos de intereses sectoriales. Más allá de su resultado concreto, cada lucha prefigura y contribuye a

\footnotetext{
${ }^{1}$ Esta fue una lucha emblemática en contra de la privatización del frigorífico testigo en el barrio de Mataderos en Buenos Aires en enero de 1959. La ocupación de la fábrica por unos cinco mil obreros se convirtió en una batalla campal con las unidades del Ejército enviadas a desalojarlos. Véase Ernesto Salas. La resistencia peronista: la toma del frigorífico Lisandro de la Torre. Buenos Aires: CEAL, 1990, 2 vols.
} 
las luchas posteriores convirtiendo la memoria de haber luchado en un elemento poderoso de la percepción colectiva.

El nexo entre luchas, experiencias y prácticas clasistas lo constituye la memoria. De hecho, la memoria sería la forma en que se recuerdan hechos en un momento (necesidad) determinado. La memoria no es ideología, ni tampoco es un relato del pasado, si bien es cierto que no son excluyentes y que hay una fuerte articulación entre ellos. La historia (en particular la oficial) presenta límites y vectores de fuerza para tratar de moldear la memoria. Pero en general tiene un éxito limitado, y las personas (y los grupos sociales) resignifican la historia para incorporar "su" memoria o sea el cómo procesan e interpretan "su" experiencia.

La memoria siempre es selectiva y siempre se hace desde las necesidades y los problemas de hoy. Nadie se acuerda de todo, sino que recurre a aquellos elementos que le son útiles adaptándolos y transformán-dolos según su necesidad. En este sentido la memoria jamás es "la verdad" sino que es una especie de reservorio selectivo de experiencias, donde los recuerdos se articulan entre sí a través del prisma de las necesidades actuales. Como tal, la experiencia jamás desaparece, sino que el mismo hecho conforma una memoria distinta según el momento histórico. Sin embargo, el hecho de que la memoria no desaparece no implica que la experiencia siempre exista en la conciencia, sino que puede ser relegada al inconsciente y subsistir como algo no constructivo sino como sensaciones de injusticia y de furia o también de apatía. Así la memoria puede ser modificada, fragmentada, postergada e inclusive relegada, pero nunca es inexistente.

Según Raphael Samuel "la memoria, lejos de ser un mero dispositivo de almacenamiento o un receptáculo pasivo, [...] es una fuerza activa y modeladora que es dinámica [...] y que se relaciona de manera dialéctica con el pensamiento histórico [...] a su manera, se trataba de un modo de construir conocimiento."2 Basándose en Maurice Halbwachs, Samuel plantea que la memoria es subjetiva. Pero, al mismo tiempo, la memoria combina una percepción de la experiencia personal con una percepción del conjunto social, para ir definiendo un accionar y una visión particular de la historia. Esto implica también que el registrar la memoria de un grupo social implica adentrarse en su subjetividad.

Lo anterior es sugerente en cuanto a los trabajadores argentinos y su construcción de la memoria de su accionar durante una dictadura represiva como lo fue la de 1976 a 1983. Esta memoria se basa en recuerdos, anécdotas y tradiciones, tanto personales como colectivas, y sirve no para construir una historia sino para establecer una identidad clasista que subyace lo que Tim Mason denominó "la oposición obrera" 3 Mason había encontrado, en su extensa

\footnotetext{
2 Raphael Samuel. Teatros de la memoria. Pasado y presente de la cultura contemporánea. Valencia: Universitat de Valencia, 2008; pág. 12.

${ }^{3}$ Tim Mason. Social Policy in the Third Reich. The Working Class and the 'National Community'. New York: Berg, 1993. Esta obra recopila los estudios de Mason sobre el tema que fueron publicados, en alemán, entre 1971 y 1977. Su proyecto de investigación no pudo ser completado antes de su muerte en 1990.
} 
investigación sobre los trabajadores alemanes bajo el nazismo, que la represión absoluta había resultado en un aniquilamiento del activismo y la militancia obrera. Sin embargo, también encontró que esto no había llevado a los obreros alemanes a una apatía y quietud. Por el contrario, Mason descubrió niveles de conflictividad y lucha que aprovechaban las características particulares del régimen. Más aun, lo que encontró Mason, a partir de revisar una extensa documentación disponible sobre la política social nazi, era que la actividad de los trabajadores, a partir de criterios y tradiciones que conformaban una clase social, tenía efectos que se podían percibir en la superestructura política como límites o frenos concretos a los objetivos del nazismo. No es que se plantee que la clase obrera "siempre lucha", sino más bien que es ilógico que una clase movilizada, con fuertes niveles de organización y tradiciones izquierdistas, simplemente se llamara a la quietud de la noche a la mañana.

Por su parte, el sociólogo James Petras estudió a los trabajadores argentinos para descubrir que éstos habían desarrollado lo que él definió como "redes familiares, sociales y políticas en torno a las cuales organiza su vida". En este sentido, Petras notaba que existía una diferencia entre el obrero y sus dirigentes o "clase política". "Las relaciones, actividades, valores, y posición social [del obrero común] son distintos de aquellos de la clase política, aún cuando comparten con esta clase una membrecía organizativa en común, un comportamiento electoral, y una oposición a los militares y la clase dominante. Sin embargo, existe una subcultura que une a la clase obrera independientemente de la organización formal, que abarca parentesco, vecindario, lugar de trabajo y clubes sociales. Estas experiencias en común separan a la clase obrera de la 'clase política'. Estas diferencias se manifiestan en formas distintas de expresión, y fundamentalmente en la noción de compañerismo, que surge de compartir la vida cotidiana, los eventos sociales, las tragedias, los eventos deportivos."4

La imagen más difundida del comportamiento de la clase obrera argentina durante la dictadura de 1976 a 1983 ha sido sintetizada por el sociólogo Francisco Delich, constituyendo una especie de "historia oficial". ${ }^{5}$ Analizando el período 1976-1981 (los gobiernos de los generales Videla y Viola), Delich planteó que "durante cinco años, la clase obrera argentina y sus sindicatos permanecieron, en conjunto, inmóviles desde el punto de vista social y de la actividad sindical

\footnotetext{
${ }^{4}$ James Petras, "Terror and the Hydra: The Resurgence of the Argentine Working Class"; en James Petras, et al., Class, State and Power in the Third World. New Jersey: Rowman and Littlefield, 1981, pág. 259.

${ }^{5}$ Francisco Delich, "Desmovilización social, reestructuración obrera y cambio sindical", en Peter Waldmann y Ernesto Garzón Valdés, El poder militar en la Argentina, 1976-1981. Buenos Aires: Editorial Galerna, 1983, págs. 101-116; y "Después del diluvio, la clase obrera", en Alain Rouquié, comp., Argentina, hoy. México: Siglo XXI, 1982, págs. 129-151. Otros trabajos lidian más que nada con el rol de las cúpulas sindicales durante el PRN, generalmente ignorando al conjunto de la clase o minimizándola como sujeto de estudio. Un buen ejemplo de esto es el trabajo de Alvaro Abós, Las organizaciones sindicales y el poder militar. Buenos Aires: CEAL, 1984. Un intento interesante de abarcar ambos niveles es el trabajo de Arturo Fernández, Las prácticas sociales del sindicalismo. Buenos Aires: CEAL, 1985.
} 
respectivamente, o bien cuando se movilizaron lo hicieron mutando formas de acción".6 Por lo tanto, "o bien no hubo acción sindical o cuando la hubo marcó distancias con el pasado", llegando a una desmovilización que representa un quiebre con la década anterior. Escribe Delich: "Este es, desde 1955, el más extenso período de inmovilidad sindical que se registra. No faltaron, como se ha expresado, motivos de agravio como para justificar la reacción obrera organizada; si ella no se produjo en una coyuntura suficientemente prolongada es porque seguramente reconoce razones que están más allá de la dialéctica de agravio-reacciónrepresión-nueva reacción, y que se instalan en otro nivel del análisis y de la historia: el de las condiciones estructurales de la acción obrera y de su transformación y de sus posibilidades". ${ }^{7}$ El resultado de todo esto sería la ruptura de la solidaridad obrera y el debilitamiento sindical y así "el obrero productor comprobó la transformación de su ámbito de sociabilidad en un ámbito de pura productividad y mecanización". ${ }^{\circ}$

Los planteos de Mason y Petras llevan a repensar las conclusiones de Delich sobre la actitud de la clase obrera argentina y reconsiderar lo que todos suponíamos que había sido una quietud frente a una agresión despiadada ante la dictadura de 1976-1983. La reacción de la clase obrera ${ }^{9}$ frente a esta agresión incluyó una amplísima gama de actividades y conflictos que abarcaban desde apoyo a familiares de delegados detenidos y desaparecidos, hasta formas de organización clandestinas, sabotajes, huelgas. Esa reacción pudo ser registrada tanto en la documentación y los archivos disponibles como en docenas de entrevistas a trabajadores del conurbano de la ciudad de Buenos Aires. En todos los casos llama la atención que la vasta mayoría de los entrevistados consideraban que "no había pasado nada" para luego relatar su experiencia de resistencia como si hubiera sido única. Eso era así aun en aquellos casos donde se repetían las formas de organización y lucha, y donde era evidente que había nexos regionales o zonales. La hipótesis que aquí se desarrolla es que lo que parece ser una forma de esquizofrenia en realidad es una manera de reconciliar la experiencia vivida con lo que es aceptado e impulsado como la verdad histórica, constituyendo una memoria particular que se ancla en "estructuras de sentimiento" y en un fuerte contenido de "nosotros contra ellos".

En particular cuatro de las entrevistas revisadas ${ }^{10}$, con cinco obreros, resultan reveladoras del problema entre la articulación dialéctica de la memoria, la

\footnotetext{
${ }^{6}$ Delich, "Desmovilización social...", pág. 101.

7 Ibid., 147-148.

8 Delich, "Desmovilización social...", p. 107. Es de notar que la base de la ofensiva por parte del gobierno radical en contra de los sindicatos peronistas, a principios de 1984, se encontraba en esta apreciación. El fracaso de la gestión del Ministro de Trabajo, Antonio Mucci, ante la unidad obrera en defensa de sus sindicatos muestra a las claras lo errado de este análisis.

${ }^{9}$ Esto fue publicado en Pablo Pozzi. Oposición obrera a la dictadura 1976-1982. Buenos Aires: Editorial Contrapunto, 1987 y Buenos Aires: Editorial Imago Mundi, 2010 (reedición ampliada y revisada)

10 Véase el acervo de entrevistas en el Programa de Historia Oral, Instituto Interdisciplinarios de Estudios de América Latina (INDEAL), Facultad de Filosofía y Letras, Universidad de Buenos Aires.
} 
experiencia particular, y la preservación de tradiciones que permiten la identidad clasista. Los cinco entrevistados eran todos obreros industriales, pero de generaciones, filiaciones políticas, y calificaciones distintas. Ramón y Lolo eran dos obreros "viejos", mayores de 60 años cuando fueron entrevistados, mientras que Aníbal, Jorge y Pete rondaban los 30 años de edad. Ramón era de nacionalidad paraguaya y había emigrado a la Argentina en la década de 1950, perseguido por la dictadura del general Alfredo Stroessner y era un obrero de la construcción al igual que Pete. Ambos tenían una alta calificación y oficio ya que uno era "colocador" de obra y el otro cañista de alta presión. Ambos eran miembros del Partido Comunista (PCA), una organización con mucha fuerza en el gremio de la construcción de la época. Aníbal, obrero de la carne, había sido activista de Acción Católica, si bien luego pasó a revistar en las filas del PCA, mientras que Jorge pertenecía al sindicato metalúrgico y militaba en el trotskismo. A su vez Lolo era un obrero "foguista" (o sea, que se dedicaba a la caldera de la fábrica), afiliado a la Unión Cívica Radical ${ }^{11}$, que tenía una alta calificación y el respeto de sus compañeros hasta el punto que recibía el trato de "Don". A diferencia de los anteriores, Don Lolo jamás había desarrollado una militancia política o un activismo sindical. En cierto sentido, testimoniantes como Don Lolo sirven de control a las interpretaciones que brindaban los obreros con militancia política izquierdista. De ahí que lo importante son los temas recurrentes, o sea que se repiten en ambas instancias, y que sugieren la posibilidad de constantes en la subjetividad que trascienden la formación política o la educación formal. Esto no quita que estas constantes se deban a influencias externas, como por ejemplo criterios derivados de las interpretaciones que se encuentran en los medios de comunicación de masas. Sin embargo, a partir del paradigma indiciario ${ }^{12}$ elaborado por los historiadores Carlo Ginzburg y Sidney Chaloub, las reiteraciones en la subjetividad de distintos individuos sin conexión entre sí, sugiere un inmenso rompecabezas donde una vez descartadas las respuestas imposibles lo que queda, por improbable que sea es lo que debe haber ocurrido.

Todos los entrevistados sabían que lo que se buscaba era que contaran cuál había sido su experiencia como obreros durante la dictadura. Asimismo, el contexto y la época de la entrevista es importante: la dictadura había terminado apenas cinco años antes y era tema de debate en todo el conjunto social argentino, particularmente en torno a la existencia, o no, de formas de resistencia o de colaboración con los golpistas. Si Delich señaló que la gran mayoría apoyó al golpe de estado, y los entrevistados lo niegan en la construcción de su memoria, entonces ¿qué significa esto para el esfuerzo de la historia oficial de construir una historia hegemónica colaboracionista?

\footnotetext{
${ }^{11}$ La Unión Cívica Radical fue un partido político que se remonta a 1890, con prédica entre los sectores medios argentinos, cuyo ideario es una adaptación del radicalismo español.

12 Véase, en particular, la "Introdução. Zadig e a história" en Sidney Chaloub. Visões da liberdade. São Paulo: Compahia das Letras, 1990.
} 
La contradicción señalada existe inconscientemente en las entrevistas $y$, al mismo tiempo, es probable que determinara que los entrevistados eligieran comenzar su testimonio estableciendo su posición respecto de esta discusión que serviría para anclar toda su participación en la construcción de la entrevista. Así, por ejemplo, Don Lolo comenzó explicando que: "La gente no hacía nada porque es un establecimiento, -- ¿cómo te voy a decir?-- no son luchadores de frente. Si el patrón viene y dice hay diez pesos de horas extras, todo el mundo contento". ${ }^{13} \mathrm{~A}$ su vez Aníbal expresó en su primera intervención: "Yo trabajaba en una fábrica grandísima, con 1.700 obreros, el frigorífico Pedró Hnos., aquí en Banfield. Prepararon todas las condiciones, cuando fue el golpe de estado fue el día que hubo mayor presentismo a pesar de la incertidumbre [...]. La gente, con mucho temor, se vino a laburar ${ }^{14}$. Yo creo que no hubo un argentino en ese momento, a no ser un tipo esclarecido, que no decía que eso tenía que terminar, que vinieran los militares."15 A su vez Pete dijo: "Nosotros estábamos en contra del golpe. La víspera del golpe estábamos en Chingolo, hablando con unos compañeros, creo, y decíamos que era tarde. Porque se veía venir, era como ver una lluvia que viene acercándose. La gran mayoría lo pedía."16

En los tres casos es notable lo que señalan y lo que silencian, sobre todo porque dos de ellos eran comunistas mientras que Lolo no sería considerado como un obrero politizado o de izquierda. Por lo pronto los tres opinaron que "nadie hizo nada". Pero, al mismo tiempo, tomaron distancia personal de esa afirmación. Para Don Lolo fue "la gente" la que no hizo nada, y de hecho no se incluye en el colectivo; para Aníbal la excepción fueron "los esclarecidos"; mientras que Pete hace una clara distinción entre "nosotros" y "la gran mayoría". No se trata de disputar si el golpe militar de 1976 tuvo apoyo popular o no, lo que interesa aquí es señalar que los entrevistados comienzan su relato a partir de parámetros concretos. En cierto sentido, lo que parecen decir es que aceptan la versión oficial por la cual "todos los argentinos fueron golpistas", pero como esto no concuerda con su experiencia personal, entonces se ven obligados a diferenciar al conjunto social (incluyendo a sus compañeros trabajadores) de sus propias vivencias. De esta manera los entrevistados se ubican dentro de los criterios "aceptados". Sin embargo, la forma de hacerlo es importante y no sólo revela una subjetividad que niega la historia oficial sino que en realidad sienta las bases para generar una contrahistoria.

\footnotetext{
13 Entrevista con Don Lolo, obrero de la fábrica Fabril Financiera, en el barrio de Barracas, ciudad de Buenos Aires. Realizada por Pablo Pozzi, el 7 de junio de 1988, en la casa del entrevistado en Villa Obrera, Lanús Oeste, Provincia de Buenos Aires.

${ }^{14}$ Laburar: argentinismo por "trabajar", se deriva de la palabra italiana "lavorare".

${ }^{15}$ Entrevista con Aníbal, obrero electricista del Frigorífico Pedró Hermanos, en provincia de Buenos Aires. Realizada por Pablo Pozzi, el 3 de mayo de 1987, en la casa del entrevistador en la ciudad de Buenos Aires.

${ }^{16}$ Entrevista con Pete, obrero cañista de la construcción, de la sección mantenimiento de la fábrica Shell. Entrevistado por Pablo Pozzi, el 3 de mayo de 1987 en la casa del entrevistado en Monte Chingolo, Provincia de Buenos Aires.
} 
A partir de establecer su "excepcionalidad", que parece permitirles reconciliar lo que sería una "historia oficial" y su propia experiencia, los entrevistados comienzan un cuidadoso (aunque inconsciente) proceso de negación al manifestar la construcción de una "memoria resistente". Esta memoria resistente tiene coordenadas concretas, sobre todo en torno a la percepción de la historia como lucha o guerra de clase, central a la defensa de sus derechos y dignidad. Al decir de Don Lolo: "Porque así tengo mis derechos".

Un elemento notable en los testimonios analizados es que la construcción de la memoria en apariencia no incluye casi referencia al tema represivo. Es evidente que esto llama la atención del entrevistador que incorpora, casi de repente, preguntas al respecto. Esto no implica que no tuvieran conciencia del problema, o menos aun que no hubiera represión. Por ejemplo, cuando se les preguntaba por el tema explícitamente, la respuesta era concreta pero también con ciertos tonos de naturalidad, por ejemplo:

Pregunta: ¿Había miedo? Ahora, pero este fue un barrio muy golpeado... [por la represión]

Aníbal: Ahí fue cuando lo desaparecieron a Rosario, que apareció con 17 tiros en la espalda, ahí en Cañuelas. Esto fue en el '78, por ahí. Era de los nuestros. Dijeron que había sido un ajuste de cuentas entre los mismos Montoneros ${ }^{17}$. ¡Qué va a ser! Si lo sacaron de la casa. Estaba con la hija. Era delegado de la Línea 3 de colectivos, de la UTA ${ }^{18}$.

Pregunta: ¿A ustedes la represión en la fábrica cómo los afectó?

Lolo: Y, no. Porque fueron inteligentes que pisaron con pies de plomo. Hubo ese secuestro que pasó esas 24 horas y chau, nada más. Ahí la gente se asustó mucho, se amilanó. Yo se que andaba la [Policía] Federal dando vueltas alrededor de la fábrica.

Pregunta: Pero ¿había represión en la fábrica?

Jorge: La forma en que se trabajaba no me gustaba, era bastante persecutoria. Y eso fue antes del '76 y después peor todavía. [...] Desaparecidos en esa fábrica no hubo muchos, pero un montón que echaron, redujeron, hicieron un montón de cosas. Gente que empezaba a armarse para hacer algo la echaron. En esa época me acuerdo que venían a la fábrica [...] dos dirigentes. Se reunían o con el dueño o con el jefe de personal. Trataban, acordaban y después se lo daban a la Interna ${ }^{19}$. Siempre se trabajaba así. ${ }^{20}$

\footnotetext{
17 Montoneros: Organización armada político-militar peronista.

18 UTA: Unión de Tranviarios Automotor.

${ }^{19}$ Interna: Comisión Interna de fábrica, el organismo de base de los sindicatos argentinos.

20 Entrevista con Jorge, obrero metalúrgico de la fábrica Littal, en Avellaneda, provincia de Buenos Aires. Entrevistado por Pablo Pozzi el 8 de agosto de 1988, en la sede de la Unión Obrera Metalúrgica, seccional Quilmes, Provincia de Buenos Aires. Jorge militaba en el Movimiento al Socialismo, una organización trotskista dirigida por Nahuel Moreno (Hugo Bressano).
} 
Este aspecto es muy interesante, sobre todo por la forma de expresarse. Cuando Jorge concluyó "siempre se trabajaba así", está resumiendo una estructura de sentimiento sobre la vida obrera en general: el trabajador se desempeña normalmente en un ambiente represivo. Al decir de Robert Linhart: "La fábrica está pensada para producir objetos y triturar hombres". ${ }^{21}$ Subyacente a esto, los entrevistados estaban expresando una percepción, que sólo puede ser explicada como una vivencia de clase, profundamente diferente a la del entrevistador. Como universitarios pertenecientes a los sectores medios, los investigadores tendían a compartir la opinión que la represión salvaje comenzó con el golpe militar de 1976. Esta no es la realidad de los entrevistados; el "sentido común" de los trabajadores les decía otra cosa. Por ejemplo, Jorge ubicó la represión desde "antes de 1976"; y Ramón, cuando se le preguntó si hubo represión en construcción, respondió: “Si, la represión empezó en el ‘5922. No fue sólo del '76. Cuando vino la intervención de julio del '59, empezó la lista negra y se mantuvo hasta ahora." Esto indicaría que, en la percepción de estos obreros no hay un correlato entre represión y dictadura, ya que las entrevistas indican que esta es permanente. En ese sentido, la represión tiende a naturalizarse como algo objetivo de la realidad, y por lo tanto no hace falta recordarla ya que su excepcionalidad no es tal. Hasta dónde esto es parte de la percepción de los entrevistados y no de la subjetividad obrera en general es un tema complejo de dilucidar. Más aun, si la experiencia individual y/o colectiva marca los límites y los significados de la subjetividad entonces es lógico suponer que la subjetividad obrera no es la misma que la de los sectores medios. Los indicios disponibles, vía autobiografías, relatos y una cantidad de entrevistas sugieren que la represión es una contracara de todo relato obrero. Esto parece indicar que los entrevistados aceptaban la violencia como algo cotidiano y parte del mundo hobbesiano en el que viven, o sea como algo "natural". Por eso al entrevistador le llama la atención que el tema no se explicitara en las entrevistas a menos que se realizara una pregunta directa, mientras que para los obreros estudiados era innecesario ya que era un supuesto conocido.

Un elemento central a la historia oficial es lo que se puede denominar "quietismo" o despolitización. Es evidente que las entrevistas abarcan este tema específicamente para poder comparar la memoria de los entrevistados con la historia oficial. Por ende las entrevistas incluyen preguntas específicas sobre el activismo obrero y la militancia política. Las respuestas son tan ilustrativas como aquellas sobre el tema represivo: en todos los casos señalan que, por lo menos en

\footnotetext{
${ }^{21}$ Robert Linhart. De cadenas y de hombres (L'établi). México: Siglo XXI editores, 1989; pág. 108.

${ }^{22}$ La referencia es notable ya que Ramón es comunista. El año 1959, durante el gobierno electo de Arturo Frondizi, se aprobó el Plan Conmoción Interna del Estado (CONINTES) dirigido en contra del activismo sindical. Ese fue el año de la huelga, ya mencionada del Frigorífico Lisandro de la Torre, y también el año de las grandes huelgas bancarias. En general los historiadores aceptan ese año como una fecha importante para el sindicalismo peronista. Ramón está sugiriendo que la fecha es importante para el conjunto de los trabajadores, y también indica que un gobierno "democrático" puede ser también represivo.
} 


\section{Argentina 1976-1983: la oposición obrera a la dictadura}

aquella época, la política y en particular la de izquierda, era parte de la vida cotidiana. Por ejemplo:

Pregunta: Usted, ¿vio volantes, cosas por el estilo?

Ramón: Aparecía, pero muy poquito. Un largo tiempo después del golpe. El que más trabajaba en el gremio era la fracción en los colocadores. Una fracción trotskista. Eran los primeros que salieron con sus volantes. Denunciaban las condiciones de trabajo y todo eso.

Pregunta: ¿Quién? ¿El PST?

Ramón: Más bien tiraba para el ERP. Y la gente decía que tenían razón.23

Pregunta: ¿Problemas con la subversión no tenían adentro?

Lolo: Yo no tuve ninguno.

Pregunta: ¿No se imprimían los volantes de los Montoneros?

Lolo: Se los imprimían. Escúchame ahí se hacía cualquier cosa. Aparecían volantes por todos lados. Una vez pusieron una bandera comunista arriba de la torre de obras sanitarias que está adentro de la fábrica. ...Después del golpe. El golpe fue en el '76. Y bueno ahí apareció una bandera. ¿Quién la puso? No sé. [Risas] Pero le querían cortar el cogote al director de la fábrica. Aparecían volantes pegados... Los volantes, es muy simple en Fabril. Yo sabía que eran todos de Mao ${ }^{24}$. Mirá, a mi me pegaban volantes en la caldera. Venía el peronista y me pegaba uno. Venía otro que era comunista y me pegaba uno.

Pregunta: Entonces ¿vos sabías quién era peronista y quién era comunista en la fábrica?

Lolo: Eran todos compañeros. Uno me quería enganchar a toda costa que tenía que ser comunista. Y yo le digo: 'Mira, vamos a hacer una cosa, afíliate al radical y yo al comunista'. Y esas cosas. Discutíamos pero de compañeros. [...] Es una gran familia.

Observemos cómo ambos, Ramón y Lolo, establecen que existía una actividad política constante como algo perfectamente natural y cotidiano. Al mismo tiempo no les hace falta decir que nadie denunciaba a los militantes políticos. Más aun, cuando Lolo declara que "no tuve problemas con la subversión", queda implícito que el problema era para la patronal ya que los militantes estaban del lado de la clase obrera. Inclusive, la expresión de Ramón "la gente dice que tenían razón" es ilustrativa de ello, lo mismo que cuando Lolo señala que "discutíamos, pero de compañeros". La expresión "una gran familia" abarca a todos los trabajadores dentro de la fábrica y, sin necesidad de decirlo, excluye a la patronal. Inclusive es notable que Lolo insistía a través de la entrevista que a él no le gusta "la política" ya que "somos gente de trabajo". Sin embargo, toda su memoria se encuentra salpicada con referencias políticas. Por lo tanto ¿a qué se puede estar

\footnotetext{
23 PST: Partido Socialista de los Trabajadores, organización trotskista que luego conforma el MAS. ERP: Ejército Revolucionario del Pueblo, una de las organizaciones guerrilleras argentinas más importantes de la época. Su dirección política era el Partido Revolucionario de los Trabajadores, de orígenes trotskistas y luego de orientación guevarista.

${ }^{24}$ Se refiere al Partido Comunista Revolucionario, de orientación maoísta.
} 
refiriendo? Lo más probable es que Lolo haya entendido "a la política" como algo que realizan los "políticos profesionales", mientras que el quehacer político familiar o del activismo fabril es algo entendido como distinto. Asimismo, subyacentemente lo que parece sugerir Lolo es que dedicarse a la política no es trabajar. Tal como señaló Petras, esta percepción o "estructura de sentimiento" es producto de cuatro características fundamentales de la clase obrera argentina. Estas son: 1) un alto grado de solidaridad y organización de clase; 2) un rechazo generalizado a los valores y la dominación del Estado y de la burguesía; 3) una clara noción de intereses de clase con un bajo nivel de mistificación, que se evidencia en el rechazo a sacrificar su estándar de vida a cambio de un ilusorio "desarrollo nacional"; y 4) poderosos lazos informales, expresados a través de la familia, el vecindario y el lugar de trabajo, que refuerzan la unidad de la clase en contra de la clase dominante. ${ }^{25}$ Todo esto apunta a una subjetividad vibrante basada en la permanente, e inconsciente, resignificación de términos, expresiones y nociones en apariencia compartidos con otros sectores sociales.

Lo anterior contribuye a explicar el surgimiento de nuevos activistas obreros, aun en condiciones de fuerte represión. Por ejemplo:

Pregunta: ¿Cómo surgen los activistas?

Pete: El tema de tomarse un vinito a escondidas, pelar una petaca de ginebra cuando hace frío, es un tema obligado para charlar. Se van conociendo. ¿Sabés cómo se conocen? Fulano es un tipo que va al frente. Fulano es un tipo que sabe, dice otro. Fulano es un tipo que es muy capaz en el laburo, y tiene muy buena parla ${ }^{26}$. Fulano sabe lo que vale su trabajo. Pero a su vez lo transmite, y así enseña lo que vale el trabajo de todos. La gente se va conociendo así, va reconociendo determinada gente. Aunque nadie diga si fue o no dirigente gremial, y la gente no comparta su historia personal o política. Y cuando se dan los problemas (económicos, accidentes) necesariamente o salen o la gente misma los saca a relucir. Che, ¿qué hacemos?, les preguntan. Surgen formas organizativas.

Aníbal: Yo te iba a decir... yo vengo desde la otra vereda. En esa época no tenía militancia. Era muy embromado para todos bregando que había que organizarse, porque yo reconozco ahora, con otra visión, que había tanto descreimiento con el que trataba de organizar. Primero porque generalmente, el que trataba de organizar era de tendencia izquierdosa. Había miedo a juntarse con ellos. [...] Yo les tenía miedo a los rojos. Y el día que dije 'aquí hay que hacer algo, hay que cambiar la cosa', miré y para el único lado que miré fue para donde estaban los que estaban todos pintados de rojo. Que eran los que estaban haciendo algo desde el principio. Me guié por ellos porque eran los únicos tipos que se habían estado jugando...

25 Petras, op. cit, 260-261.

${ }^{26}$ Parla: argentinismo para "hablar", proviene del italiano "parlare". 
Lo que llama la atención es que politización y el compromiso no están anclados en un convencimiento o en un "despertar" ideológico. En ambos casos la explicación parte de la experiencia personal que combina necesidad, con el reconocimiento positivo de la actividad militante, y un criterio por el cual la lucha obrera tiende naturalmente a acercarse a la izquierda. Aníbal parece decir que la realidad obrera, no la ideología es lo que lo llevó desde Acción Católica al Partido Comunista. Esta realidad se expresa no tanto en propuestas programáticas si no en una praxis que genera lo que se podría denominar "líderes naturales". Así para Aníbal es importante que "se la estaban jugando", mientras que para Pete lo crucial es que "Fulano sabe lo que vale su trabajo" y lo transmite. Por ende los entrevistados, ya sea un obrero que no es "de izquierda" como Lolo, u otro que comienza "con miedo a los rojos" como Aníbal, o un militante como Pete, lo que transmiten es un "sentido común" donde los obreros de izquierda también son considerados parte de "la gran familia" trabajadora.

Todo lo anterior sirve para expresar lo que los entrevistados parecen considerar "el momento clave", o sea el relato de su protagonismo histórico. Así la narración de cada uno tiene una progresión cuasi lineal: parte de una aparente aceptación de la historia oficial, para luego plantear su carácter de testimoniante excepcional (o sea distinto a la media) y no colaboracionista; de ahí pasan a establecer un "nosotros y un ellos" que reafirma su identidad como obreros en contraposición a otros sectores sociales; luego centran su narración en el momento de lucha o sea en la "prueba" de que ellos si se opusieron a la dictadura; y, como veremos más tarde, van a concluir con una lección dirigida al conjunto de los trabajadores. En este sentido el criterio clasista construye una memoria de lucha contestataria y opositora a los objetivos dictatoriales y de la burguesía, que al mismo tiempo reafirma una identidad obrera y una centralidad de su protagonismo histórico como sector social.

Todo lo anterior se combina para sugerir la existencia de una praxis anclada en el "sentido común" implícito en una "cultura ordinaria" obrera, en la acepción de Raymond Williams ${ }^{27}$. Esto invierte nuestra percepción de la conflictividad obrera: en vez de entenderlo como un producto de decisiones "desde arriba" (de liderazgos o de propuestas ideológicas), la combatividad de los obreros argentinos debería ser considerada "desde abajo", o sea como algo que emerge de la realidad vivida para gestar prácticas de lucha concretas. Por ejemplo, según Lolo:

[...] les digo a mis compañeros, 'vamos a cortar las horas extras porque estos señores nos están sacando la categoría a nosotros'. [...] Y porque, ponele se pedía un aumento, se decía que no, y ahí nos reuníamos. Cortamos las horas extras. En la época del Proceso ${ }^{28}$ cortamos las horas extras y todo. Y las cortamos porque nos prometían un $5 \%$ de aumento, esperábamos varias fechas y nunca venía. Lo

\footnotetext{
27 Véase Raymond Williams. "Culture is Ordinary" (1958). En Williams. Resources of Hope. London: Verso Books, 1989.

28 Proceso: La dictadura de 1976 a 1983 se autodenominó "Proceso de Reorganización Nacional”.
} 
hicimos varias veces. Hemos vivido oprimidos. Mirá yo en la época del Proceso tuve una agarrada muy grande con un tal Pons, jefe de relaciones públicas. Entonces, él nos quería sacar un convenio que yo lo había conquistado. Yo lo había conquistado, de que a los 20 minutos me tenía que retirar. 0 sea cumplíamos siete horas 40. Trabajábamos 7 horas y media, y ahora ocho horas, y nos pagaban ocho y media. Entonces, cuando yo llego nos mandaba a trabajar los sábados a la tarde normal. Los sábados a la tarde es 100 por 100. Éramos siete u ocho, venimos y nos encontramos que trabajaban ocho horas los sábados a la tarde. En caldera trabajábamos tres foguistas, porque sacaron el turno de noche. [Esto fue en el] '78 sería, más o menos... Y le digo a los compañeros: 'Perdónenme que se los diga pero cuando me toque a mi venir de tarde si no me lo pagan el 100 por 100 paro la caldera. [...] Pero un compañero, que sabía mucho de leyes, empezó a pelearla, hasta que cada cual a su turno y tuvieron que pagar lo que correspondía. [...] Yo no tuve miedo, yo hablé. Yo estuve casi seis meses cortándole las horas extras, hasta que me mandaron a lo que me correspondía.

La construcción de una memoria cuasi mítica es evidente. Lolo se convierte en el protagonista, y por ende en la expresión del conjunto de la clase. El tema de "no tener miedo" hace a su machismo, pero también a la construcción de una identidad digna en un contexto donde "hemos vivido oprimidos". Pero, al mismo tiempo, como obrero viejo imbuido en las tradiciones y el sentido común colectivo, siempre regresa a un "nosotros", donde su relato articula una memoria en función de la construcción de una historia de dignidad y de lucha. Así la expresión "hemos vivido oprimidos" no sólo ubica su relato en la tradición colectiva, sino que implica una crítica al sistema social en su conjunto, y contrapone el "nosotros" a "ellos" representado por el jefe de relaciones públicas. Claramente, Lolo está presentando una visión política e ideológica, aunque él la perciba no como tal sino como "sentido común" emergente de su realidad como trabajador.

No sabemos hasta dónde es verídico lo que relata Lolo, como no sabemos si su protagonismo fue tal. Pero lo importante, para Lolo, no es la veracidad de lo que dice. Al igual que los ferroviarios que citamos al principio, lo que importa es dejar en claro que no hubo una aceptación pasiva, y si bien Lolo puede no haber sido el protagonista de este conflicto, lo real es que puede haberlo sido, él u otros. La conclusión del relato de Lolo debería ser obvia: en su memoria, y en su aporte a la memoria colectiva y por ende a una "contrahistoria oficial" de la clase obrera, no hubo pasividad obrera ante la dictadura. Lo que hubo, al decir de Tim Mason, fue una "oposición".

El relato de Lolo es difícil de constatar, porque aun si entrevistáramos a varios de sus compañeros, es factible que el relato de "oposición" se haya sedimentado en una estructura de sentimiento determinada. Lo que le da visos de probabilidad, y gesta indicios que lo hacen creíble, es la cantidad de otras historias de lucha que si se pueden constatar. Jorge relató la suya, y si bien los detalles son propios de esa historia silenciosa y oculta de la clase obrera, los grandes rasgos de la misma se pueden constatar en la prensa de la época y en la documentación 
disponible en el Archivo de la Memoria de la Provincia de Buenos Aires. ${ }^{29}$ Lo notable del testimonio de Jorge es su esfuerzo por ser preciso en lo que relata. Esto lo hace en función de lo que suponemos él entiende un deber político como "obrero consciente": el de transmitir una experiencia de lucha y organización. Con sus recuerdos Jorge parece querer aportar a construir una memoria que contribuya a la historia colectiva de la clase obrera argentina. Así, Jorge recuerda:

La experiencia que voy a contar es la lucha que tuvimos cuando se vino abajo la fábrica. Era Littal S.A. Está ahí en Belgrano y Vélez Sarsfield, en Avellaneda. A dos cuadras del sindicato. Una ferretería. [Éramos como] trescientos y pico. Fueron achicando, achicando, achicando. Cuando fue la gran lucha éramos 160. Bueno, ahí dominaba netamente la UOM Avellaneda ${ }^{30}$. No se hacían asambleas ni nada si no venía un dirigente del gremio. [...] Después siempre que tratabas de hacer algo se acordaban entre el gremio y la patronal y te rajaban ${ }^{31}$. Entonces hicimos un trabajo distinto entre un grupo de compañeros. Nos empezamos a meter junto con la burocracia, nos empezamos a meter en el sindicato. Íbamos allá, nos reuníamos con ellos, tratando de disimular la forma de pensar, hacíamos oídos sordos a muchas cosas, reventábamos de bronca pero nos callábamos, y fuimos trabajando así. De esa forma, porque ahí cuando se elegía delegado estaba todo preparado anteriormente. Una vez que estábamos firmes empezamos a dar la cara quiénes éramos. Había compañeros de todo tipo de ideología, había de todo. Pero era una cosa muy tapada por el momento. La dictadura no era joda32. Mayoritariamente eran peronistas los compañeros. Éramos más o menos 12 o 14, casi un $10 \%$. Un grupo bastante fuerte.

Cuando llega este compañero a la Comisión Interna se empieza a polarizar dentro de la Interna. Resulta, claro, que los métodos de unos chocaban con los métodos de otros. No sólo las ideas, sino los métodos. Nosotros en el taller no pasaba una semana que no teníamos una asamblea. Y los otros no hacían nada. Porque querían digitarlo todo, los delegados con el gremio, y que la gente se entere después. Ya empezaron los choques. Y el grupo fuerte del equipo que tenían de activistas, que estábamos dentro de la agrupación, nos fuimos separando antes de que nos pase algo. Agarramos y empezamos a trabajar en equipo. Y ahí nos hicimos fuertes, por

${ }^{29}$ El Legajo 133, un dossier elaborado por los agentes de la DIPBA después de los primeros años de represión (fecha relativa, marzo de 1979 o 1980), presentaba un balance de la situación laboral en las grandes industrias (100 empresas) donde existieron conflictos obreros antes del golpe militar de 1976 (merma de producción, suspensiones, despidos, sabotajes, ocupaciones, atentados a directivos). El título del documento es: Principales establecimientos fabril-industrial de la Provincia de Buenos Aires que han sufrido estados conflictivos y posible infiltración subversiva. A partir de 1980, los legajos confeccionados por la DIPBA en el sector gremial registran una conflictividad obrera en ascenso, y además una preocupación por los datos económicos, las situaciones recesivas en las fábricas y la desocupación. La documentación disponible confirma los numerosos testimonios de las víctimas de la represión, y revela que las conclusiones derivadas a partir de la documentación circunstancial y secundaria son correctas. En particular este informe hace referencia al acceso al material documental del Archivo de la DIPBA (Dirección de Inteligencia de la Policía de la Provincia de Buenos Aires) que se encuentra en la sede de la Comisión Provincial de la Memoria, en la ciudad de La Plata.

30 UOM: Unión Obrera Metalúrgica.

${ }^{31}$ Rajaban: argentinismo por "despedir".

32 Joda: argentinismo por "chiste". 
algunas cosas que habíamos conseguido. Trabajás todo el año, pero cuando llega octubre trabajás muy fuerte. Entonces nosotros apretábamos ahí. Inclusive apretamos tan fuerte que inclusive una vez firmaron un acta de compromiso el sindicato con Littal, y nosotros en una asamblea les hicimos romper el acta, y ahí empezaron los grandes choques. Tanto con la burocracia como con la patronal. Ahora, cuando empezamos a dominar la fábrica y se veía que si había elecciones íbamos a barrer toda la Comisión Interna, hacen sondeos a ver si podía hacer rajes y eso. Y al primer síntoma... fa, un paro. Al sólo enterarnos.

El comienzo de la narración es notable: establece que la lucha "es experiencia" mientras que subyacentemente queda claro que ésta es importante. De ahí pasa rápidamente a detallar su conocimiento del tema al brindar una serie de datos sobre el establecimiento. Y luego quiere dejar asentado que la lucha era justa, especificando los agravios sufridos y estableciendo que no actuaron improvisadamente. Aquí hay dos elementos que son importantes resaltar. El primero es que, al señalar la peligrosidad de la dictadura, también esta resaltando la heroicidad de la lucha y la conciencia de los riesgos. El segundo es que esto fue cosa de obreros en su conjunto, y no de partidos políticos: "había... de todo tipo de ideología" contrapone la noción de compañero a la pertenencia partidaria.

A partir de ahí Jorge continúa su relato, estructurando una dicotomía de dirigentes corruptos, colaboracionistas y burocratizados versus obreros combativos, honestos y solidarios. Esta dicotomía es importante a la luz de que todos los entrevistados parecen aceptar la historia oficial del colaboracionismo con la dictadura. Jorge parece señalar que los que colaboraron fueron los dirigentes ("burócratas", diría él) y no los trabajadores. Y en eso deja en claro la inventiva de los trabajadores, y el hecho de que no estaban solos, sino que eran acompañados por obreros de otras fábricas:

[...] '79. Plena dictadura, estaba Videla ${ }^{33}$ todavía. [...] Cuando llega esa recesión empieza a golpear la fábrica. Se cortan las horas extras, empieza el retiro voluntario. Ahí es cuando quedan 160 compañeros. Se fue un montón de gente. Y ya empiezan a correrse las versiones que van a suspender, cerrar. ... nos debían el aguinaldo porque la crisis ya estaba, estaba el problema de las vacaciones, estaban quincenas adeudadas. Nos debían guita ${ }^{34}$. Estuvimos todo el mes de mayo luchando, luchando. Íbamos y veníamos. En el sindicato no podíamos reunirnos porque lo teníamos en contra. Empezamos un grupo, primero en bares, y después que vimos que podíamos hacer algo nos reuníamos en la parroquia ahí cerca del cementerio de Avellaneda, dentro de una villa ${ }^{35}$.

\footnotetext{
33 Videla: el general Jorge Rafael Videla, "presidente" de la Junta Militar que gobernaba el país durante la dictadura de 1976-1983. Fue sucedido por el general Roberto Viola en 1981.

${ }^{34}$ Guita: argentinismo por "dinero"

35 Villa: referencia a "villa miseria", barriada de sectores marginados signada por la inestabilidad laboral.
} 
Nos reunimos un mes. Ya teníamos la promesa de la fábrica de que iba a pagar. A la mañana no pagó. Invitamos a todos los compañeros a venir. Y vinieron un montón de compañeros, no me acuerdo cuantos, pero eran un montón. Y sobre todo compañeras, que son muy lentas para arrancar, pero cuando arrancan no las paran más. Son más fuertes que los compañeros muchas veces. Tenían miedo, pero como nos juntamos en la parroquia se animaron. No tenían más miedo. Fuimos ahí nos juntamos, propusimos qué hacer. La idea era conseguir la guita y después luchar por la fuente de trabajo. Cuando hacemos esas reuniones vienen los compañeros de la fábrica SERMA, que está en frente de Hidrodinámica Vázquez aquí en la seccional, que habían tenido un problema similar. Y en conjunto la comisión de Littal y la de SERMA fuimos a ver a los compañeros de FAE, una fábrica de SMATA que está en Avellaneda. Estábamos a punto de hacer una mini coordinadora para luchar en conjunto.

Observemos que esta parte de la entrevista gira en torno a la expresión "luchamos, luchamos". La repetición del término realza no sólo la importancia si no la constancia y la dureza del conflicto. Al incluir la mención de otras fábricas, Jorge parece indicar que esto era una constante en la realidad colectiva. Así pasa a contar el conflicto en sí:

Nos reuníamos todos esos compañeros. [...] Pero la bronca fue subiendo porque cuando fuimos a cobrar el aumento, no lo habíamos cobrado. Y esa tarde fuimos un montón de compañeros que estábamos ahí, en la puerta de la oficina de personal, todos en la calle. Y la guita no aparecía. Era un día lluvioso.

Un grupo de compañeros nos fuimos a la UOM Avellaneda, a hablar con Fernández, este dirigente que atendía la fábrica. Y medio prepoteó a dos compañeras que fueron conmigo --fuimos cinco-- y como fue prepotente vinimos para la fábrica y llevamos a todos los compañeros para el sindicato. Hicimos una reunión dentro del gremio, ahí en el salón que tienen. Y tanto fue creciendo la bronca que no mediamos dónde estábamos. Estábamos en una dictadura y en el sindicato dirigido por una de las peores burocracias. Bueno, fue tanta la apretada que se tuvo que disculpar públicamente de haber tratado mal... que estaba nervioso... Y tuvo que ponerse a la cabeza de la lucha; todo porque vio que eso crecía y crecía.

Fuimos a la fábrica, y en un momento, no sé si por fanfarronear o qué, dijo: 'bueno si acá, a tal hora, no aparece la guita, vamos a tomar la fábrica'. Fue ahí cuando nosotros le agarramos la lengua y dijimos: 'Ta bien, vamos a ver, vamos a esperar hasta esa hora, si la plata no viene la fábrica la tomamos'. Llegó la hora y no apareció nadie. Bueno, dije, 'nosotros tomamos la fábrica'. 'Bueno, pero, bueno...' 'Nosotros la tomamos, estamos podridos ya'. Bueno. Fue él el que hizo una artimaña y se fue para el lado de la portería. Más bien que los porteros no te van a abrir el portón para que entrés. Pero había un portón de costado, por donde entraban las cargas, y cuando ocurrió eso nos fuimos corriendo para el otro lado, tiramos el portón abajo y tomamos la fábrica. Cuando tomamos la fábrica aparecen los jerarcas de la empresa que quieren arreglar todo. Pero la fábrica estaba tomada. Estuvimos toda la noche y todo el otro día. Habíamos 
puesto carteles, salimos en los diarios, Diario Popular, El Quilmeño, Crónica. Fue una toma importante.

Nos pagaron todo. Pero dijeron que después que nos paguen teníamos que dejar la fábrica porque nos iban a reprimir. No nos dijeron oficialmente pero lo dieron a entender. Entonces, nosotros considerábamos que ante esa situación convenía hacer ver a los compañeros que habíamos conseguido un triunfo porque habíamos conseguido todo eso. No fue una derrota. Nos retiramos. Al otro día salió en el diario 'Ganaron la lucha'.

La memoria de Jorge establece un parámetro de dignidad y lucha aún en una cruel dictadura y "en medio de una de las peores burocracias". Habiendo dejado en claro una serie de criterios básicos, la narración va creciendo y tomando velocidad. En esa narración vamos encontrando distintas expresiones de ese "sentido común" del obrero argentino. Por ejemplo, ¿cómo sabemos que la UOM era una de las peores burocracias? Porque "prepotearon" a dos compañeras, y pegarle a las mujeres, igual que a los viejos, en su visión es una prueba categórica de maldad. De la misma manera, refrenda su conclusión de que "fue una toma importante" aclarando que la prensa la reconoció como tal; pero lo que hay que dejar en claro es que no es cualquier prensa, sino que son aquellos diarios que leían mayoritariamente los trabajadores de Buenos Aires ${ }^{36}$. Asimismo, no sólo enfatiza la combatividad sino también que lo que en apariencia es un quietismo no es tal. Esto es lo que queda claro de la referencia a "las compañeras, que les cuesta arrancar pero cuando lo hacen no paran". Esto es importante porque lo que sería una valoración machista, debería ser matizada cuando establece que "son más fuertes que los compañeros". También queda clara la inventiva en desarrollar "la oposición" cuando relata que utilizan la parroquia para reunirse clandestinamente. De hecho, la cantidad de anécdotas en los múltiples testimonios recogidos, que dejan en claro una capacidad creativa para luchar, es notable. Basta como ejemplo una anécdota de la fábrica Ford que produjo una cantidad de móviles para la Policía Federal, todos con desperfectos. Una vez desmontado el motor de algunos de estos patrulleros, la Policía de la dictadura encontró en el bloque del motor pequeños balines con cartelitos pequeños que decían "Por fin lo encontraste, hijo de puta".

De repente lo que declaran los entrevistados en un principio, que la dictadura contaba con apoyo y había apatía, no debe ser tomado al pié de la letra. De hecho, lo más probable es que esto haya sido una concesión a la "historia oficial", particularmente porque a continuación todos se esfuerzan por señalar numerosas formas de oposición y de preservar la dignidad obrera frente a la opresión. Esto es más que meros "recuerdos" y conforma la construcción de una

${ }^{36}$ El Quilmeño es el periódico zonal de Quilmes, leído sobre todo por los vecinos de la zona. Diario Popular y Crónica son los dos periódicos cuyos lectores son mayoritariamente trabajadores. Sus artículos son relativamente cortos, trae muchas noticias sindicales, además de las consabidas páginas policiales de "nota roja". 
memoria que articula un comportamiento colectivo que debería quedar claro por la conclusión que hizo Pete en su entrevista. Señaló:

[La resistencia] me parece que surge en buena parte de la gente que empezó a hacer trabajo de hormiga, de los bolsones, ¿no? Nace un poco de la necesidad de los activistas que quedaron descolgados de hacer un trabajo más organizado, de organizarse. Los partidos políticos, todos, desinflan. 'Desensillar hasta que pare la lluvia', en mayor o menor grado eso pasó con todos. Los activistas no tienen retaguardia, se tienen que acostumbrar a lo nuevo. Pero llega un momento que vos, como activista social, necesitás un grado mínimo de organización y de trabajo. No es organizado, no hay instrucción del Partido... Mejor dicho, no es centralizado. [...] No es solamente el activismo ese de los bolsones, de los activistas, sino todo el aprendizaje de las experiencias vividas en el anterior gobierno y de la historia que queda grabado en alguna gente y se expresa de alguna manera o de otra en el resto. [...] Por eso no es insólito; para esa gente es insólito; para nosotros es natural. [...] Ahí se abre un potencial humano terrible. Que lleva a los pueblos, cuando se dan los cambios sociales, a dar la vida. Sin llegar a tener la súper conciencia.

Lo notable del planteo de Pete es que reúne recuerdos para articular una memoria y desarrollar una perspectiva histórica. En cierto sentido, lo que él expone es una especie de síntesis de los criterios que subyacen a las distintas entrevistas consideradas. De ahí que señale que lo que puede ser "insólito" para el entrevistador, para él es normal y parte de la vida cotidiana. Inclusive hay que destacar que Pete es un obrero comunista, pero que lejos de centrarse en su partido político lo hace en la clase obrera como agente de cambio histórico. Esta es la comprobación práctica de lo que planteó Raphael Samuel: "la memoria [...] es una fuerza activa y modeladora que es dinámica [...] y que se relaciona de manera dialéctica con el pensamiento histórico [...]."37

La actitud de la clase obrera argentina frente a la dictadura militar que se inició en 1976 ha sido objeto de numerosas discusiones, donde la mayoría de las opiniones académicas coinciden en que se caracterizó por la apatía. La investigación disponible plantea que eso es una conclusión impresionista sin sustento empírico. De hecho, las investigaciones disponibles revelan que hubo una resistencia capilar y constante anclada en lo que Raymond Williams ha denominado "una estructura de sentimientos". Esto se visualiza en las entrevistas consideradas. La estructura de la narración, la adjetivación utilizada para transmitir una experiencia, las imágenes a las que se recurren, todo conforma una visión clasista de articular la memoria obrera. En la misma, las tradiciones, el lenguaje, y el imaginario conforman no sólo una forma de transmisión de una experiencia opositora, sino también lo que podríamos denominar una memoria clasista y por ende marcada por la guerra de clases.

${ }^{37}$ Raphael Samuel. Teatros de la memoria. Pasado y presente de la cultura contemporánea. Valencia: Universitat de Valencia, 2008; pág. 12. 
Como señalamos al principio las respuestas de nuestros entrevistados se ven fuertemente determinadas por el contexto y la época en que fueron entrevistados. ¿Dirían lo mismo hoy? La investigación disponible revela que, diez años más tarde, a mediados de la década de 1990, esa memoria de oposición obrera a la dictadura se habría modificado, donde se fusionaba casi indistintamente con otra construida a partir de recuerdos cuasi míticos de algunas experiencias anteriores como por ejemplo aspectos de la Resistencia peronista (1956-1962) o de las luchas de los obreros en la década de 1960. Es probable que los cambios en el contexto, que las nuevas necesidades surgidas a partir de la ofensiva neoliberal de la década de 1990 hayan determinado la necesidad de una memoria con nuevas características y lecciones. Pero también es importante que tomemos en cuenta que el crecimiento de la inestabilidad laboral y del desempleo hayan dificultado (o quizás imposibilitado) la transmisión de experiencia a través de recuerdos que articulen una memoria de organización y lucha.

El resultado de lo anterior para la memoria ha sido profundo. En la clase obrera argentina esta se transmitió, históricamente, por varias vías. La primera y principal era la transmisión oral en la familia, en el barrio y en el lugar de trabajo. Eran los familiares y compañeros de trabajo los que enseñaban el oficio, la tradición obrera y lo que era considerado un comportamiento digno y correcto. La fragmentación de la vida, de las barriadas, y de los lugares de trabajo, a través de todo lo que ha generado la recomposición de la clase obrera, ha dificultado la transmisión de la memoria. Otra vía de esta transmisión era el sindicato. Tanto el activismo como las escuelas sindicales forjaban una tradición que marcaba a los trabajadores de tal o cual gremio. La decadencia del sindicalismo y la transformación de muchos dirigentes en sindicalistas empresarios implican que el sindicato ya no cumple el papel de transmisor de la experiencia obrera como lo hizo en otras épocas. Todo esto implica que la memoria obrera actual no puede ser la misma que cuando fueron entrevistados estos obreros.

Cuando un ser humano cuenta su historia recurre a recuerdos y se basa en la memoria construida en ese momento para desarrollar un proceso/ progresión que intenta explicar y dar a conocer el porqué de su presente cargado de significaciones (o sea su historia) y que de alguna manera va señalando un posible futuro. La historia es mucho más que la memoria, los recuerdos o las experiencias: en realidad es la forma en que todos estos se articulan (a veces dejando unos de lado para realzar otros) en una explicación coherente del pasado desde el presente y con intención de servir como lección del futuro. De hecho, todo relato histórico encuentra resignificaciones/ oposiciones/negaciones que van desde la memoria de un sector social hasta la propia historia que construyen. Así cada uno hace su historia en base a las inquietudes (y prejuicios) y sus perspectivas (ideología) y su memoria (también modificada por época y momento). Pero sólo en algunos casos esto logra constituirse en la historia oficial. Lo central es nunca independizar la experiencia, del recuerdo, de la memoria, de la historia. El problema es cómo realizar una articulación dialéctica entre todos estos que sirva de explicación. 
Claramente la historia oficial tiene un gran peso, es más hasta puede ser un peso determinante en cómo construimos la memoria. Pero lo que hay que tratar de ver es aquello que señaló E. P. Thompson: "el marinero se puede equivocar de lo que pasa en la Corte de Versalles [y por ende, diría yo, aceptar la explicación/historia oficial] pero conoce sus mares [o sea tiene una experiencia concreta]"38. La memoria se forja, cambia, se recompone, se resignifica y casi siempre está "en solución" y pocas veces "se sedimenta" en la misma forma en que el marinero, que acepta lo que le dicen sobre Versalles, lo acomoda a lo que él siente que ha vivido (que puede no ser lo que realmente vivió). Como bien señaló Pete, nunca hay desmemoria y la experiencia de la clase obrera no se pierde sino que se resignifica de manera que "se abre un potencial humano terrible. Que lleva a los pueblos, cuando se dan los cambios sociales, a dar la vida. Sin llegar a tener la súper conciencia."

${ }^{38}$ E.P. Thompson. Miseria de la teoría. Barcelona: Crítica, 1981. 